\title{
Effect of tocotrienol from Bixa orellana (annatto) on bone microstructure, calcium content, and biomechanical strength in a model of male osteoporosis induced by buserelin
}

This article was published in the following Dove Press journal:

Drug Design, Development and Therapy

\author{
Nur-Vaizura Mohamad \\ Soelaiman Ima-Nirwana \\ Kok-Yong Chin
}

Department of Pharmacology, Faculty of Medicine, Universiti Kebangsaan

Malaysia, Kuala Lumpur, Malaysia
Correspondence: Kok-Yong Chin Department of Pharmacology, Level 17, Preclinical Building, Universiti Kebangsaan Malaysia Medical Centre, Jalan Yaacob Latif, Bandar Tun Razak, 56000 Cheras, Kuala Lumpur, Malaysia

Tel +60 $39 \mid 459573$

Email chinkokyong@ppukm.ukm.edu.my
Background: Patients receiving androgen deprivation therapy experience secondary hypogonadism, associated bone loss, and increased fracture risk. It has been shown that tocotrienol from Bixa orellana (annatto) prevents skeletal microstructural changes in rats experiencing primary hypogonadism. However, its potential in preventing bone loss due to androgen deprivation therapy has not been tested. This study aimed to evaluate the skeletal protective effects of annatto tocotrienol using a buserelin-induced osteoporotic rat model.

Methods: Forty-six male Sprague Dawley rats aged 3 months were randomized into six groups. The baseline control $(n=6)$ was sacrificed at the onset of the study. The normal control $(n=8)$ received corn oil (the vehicle of tocotrienol) orally daily and normal saline (the vehicle of buserelin) subcutaneously daily. The buserelin control $(n=8)$ received corn oil orally daily and subcutaneous buserelin injection $(75 \mu \mathrm{g} / \mathrm{kg})$ daily. The calcium control $(\mathrm{n}=8)$ was supplemented with $1 \%$ calcium in drinking water and daily subcutaneous buserelin injection $(75 \mu \mathrm{g} / \mathrm{kg})$. The remaining rats were given daily oral annatto tocotrienol at $60 \mathrm{mg} / \mathrm{kg}(\mathrm{n}=8)$ or $100 \mathrm{mg} / \mathrm{kg}(\mathrm{n}=8)$ plus daily subcutaneous buserelin injection $(75 \mu \mathrm{g} / \mathrm{kg})(\mathrm{n}=8)$. At the end of the experiment, the rats were euthanized and their blood, tibia, and femur were harvested. Structural changes of the tibial trabecular and cortical bone were examined using X-ray micro-computed tomography. Femoral bone calcium content and biomechanical strength were also evaluated.

Results: Annatto tocotrienol at 60 and $100 \mathrm{mg} / \mathrm{kg}$ significantly prevented the deterioration of trabecular bone and cortical thickness in buserelin-treated rats $(P<0.05)$. Both doses of annatto tocotrienol also improved femoral biomechanical strength and bone calcium content in buserelin-treated rats $(P<0.05)$. The effects of annatto tocotrienol were comparable to calcium supplementation.

Conclusion: Annatto tocotrienol supplementation is effective in preventing degeneration of the bone induced by buserelin. Therefore, it is a potential antiosteoporotic agent for men receiving androgen deprivation therapy.

Keywords: androgen, vitamin E, fracture, gonadotropin-releasing hormone agonists, testosterone, osteopenia, osteoporosis

\section{Introduction}

Osteoporosis is a serious but undervalued disease that affects $>200$ million people globally. ${ }^{1}$ Defined as a deterioration of bone mass and microarchitecture, it can be classified into primary and secondary osteoporosis. The former is age related or idiopathic. Although it occurs in both sexes, postmenopausal women are more commonly affected. 
Secondary osteoporosis occurs as a result of medical conditions or medications affecting bone metabolism. ${ }^{2}$ Hormonal agents, such as gonadotropin-releasing hormone $(\mathrm{GnRH})$ agonists, inhibit gonadotropins' secretion leading to a hypogonadal state that resembles menopause in women and chemical castration in men. ${ }^{3}$ Bone turnover, indicated by circulating osteoblast and osteoclast biochemical markers, increases progressively with the use of GnRH agonists. ${ }^{4}$ This results in a 5-10 times higher rate of bone loss and a $6.5 \%-17 \%$ lower bone mass in patients managed with $\mathrm{GnRH}$ agonists compared to those without. ${ }^{5,6}$ The risk of fracture at any sites in men receiving GnRH agonist was 7.91/100 (relative risk 1.21, 95\% CI 1.09-1.34) versus 6.55/100 among nonusers, with a significantly higher rate at the hip (relative risk $1.76,95 \%$ CI $1.33-2.33) .^{7}$ Thus, the adverse skeletal effects of GnRH agonists should be taken seriously.

Osteoporotic fractures in men result are associated with short- and long-term morbidities characterized by pain, limitation of function, decreased health-related quality of life, and higher mortality rates. ${ }^{89}$ It is also a significant financial burden to the patients, the health care system, and the countries due to the medical expenses involved and the loss of productivity. ${ }^{10}$ Although the existing pharmacological treatments for osteoporosis, such as bisphosphonates, denosumab, and teriparatide, are proven effective in increasing bone mineral density and reducing fractures, they come with some adverse side effects and are plagued by the problem of low compliance. ${ }^{11,12}$ The current preventive agents for osteoporosis are limited to calcium with or without vitamin $\mathrm{D}$. The search for a more effective alternative agent is intensified with increasing demands from the patients.

Tocotrienols are a subset of the lipid-soluble vitamin E family derived from plant oil, apart from the more well-known tocopherols. ${ }^{13,14}$ Studies have shown that tocotrienol exerted bone protective effects in various animal models of osteoporosis, induced by primary female ${ }^{15,16}$ and male hypogonadism, ${ }^{17}$ free radical, ${ }^{18}$ nicotine, ${ }^{19}$ and dexamethasone.${ }^{20}$ In one study of note, oral annatto tocotrienol supplementation for 8 weeks at $60 \mathrm{mg} / \mathrm{kg}$ in orchidectomized rats prevented deterioration of bone microstructures and calcium content. ${ }^{17,21}$ However, the skeletal effects of tocotrienol on osteoporosis induced by GnRH agonist have not been explored. Tocotrienol derived from annatto (Bixa orellana) bean contains $\sim 90 \%$ delta-tocotrienol, 10\% gamma-tocotrienol, and no alphatocopherol..$^{22}$ In comparison, vitamin E mixtures from palm ${ }^{23}$ and rice bran contain high amount of alpha-tocopherol. ${ }^{24}$ The unique composition of annatto tocotrienol provides an opportunity to study the bone protective effects of tocotrienol without the interference of alpha-tocopherol. Previous studies showed that the biological activities of tocotrienol were reduced with the addition of alpha-tocopherol. Of note, alphatocopherol attenuated the cholesterol-lowering effects and 3-hydroxy-3-methylglutaryl coenzyme A reductase inhibiting activities of tocotrienol. ${ }^{25,26}$ Since alpha-tocopherol competes with tocotrienols in binding with alpha-tocopherol transfer protein, a key transporter in determining the circulating vitamin $\mathrm{E}$ level in the body, the reduced biological activities of tocotrienol might be contributed by its decreased bioavailability in the presence of alpha-tocopherol. ${ }^{27}$ An in vitro study also showed that alpha-tocopherol promoted osteoclast fusion and increased bone resorption. This effect was not shared by tocotrienols. ${ }^{28}$

The objective of the current study was to evaluate the effects of annatto tocotrienol at 60 and $100 \mathrm{mg} / \mathrm{kg}$ body weight on bone microstructural indices, bone calcium content, and bone biomechanical parameters in male osteoporosis model induced by buserelin, a GnRH agonist. We hypothesized that annatto tocotrienol could prevent bone deterioration in hypogonadal male rats, and the effects would be dose dependent. We hope the findings from this study will validate the use of annatto tocotrienol as a preventive agent against male osteoporosis due to GnRH agonist.

\section{Methods}

\section{Preparation of treatment}

Natural tocotrienol from annatto (B. orellana) bean (DeltaGold ${ }^{\circledR} 70$; lot number: 4II5-AAM4-70), containing $86.3 \%$ delta-tocotrienol and $13.9 \%$ gamma-tocotrienol, was a gift from American River Nutrition Inc. (Hadley, MA, USA). It was diluted with vitamin E-free corn oil (MP Biomedicals, Illkirch, France) in a ratio of 1:10 before given to the rats. The use of vitamin E-free corn oil prevented the interaction of alpha-tocopherol on the absorption of tocotrienol.

\section{Animals and treatment}

Forty-six male Sprague Dawley rats aged 3 months were obtained from the Laboratory Animal Resource Unit of Universiti Kebangsaan Malaysia (Kuala Lumpur, Malaysia). The rats were housed individually in plastic cages at the animal laboratory of the Department of Pharmacology, University Kebangsaan Malaysia (Kuala Lumpur, Malaysia) under standard conditions $\left(27^{\circ} \mathrm{C}\right.$, natural dark-light cycle, tap water, and standard rat chow ad libitum). After a week of acclimatization, the rats were randomized into six groups. The baseline control group ( $\mathrm{n}=6)$ was sacrificed at the onset of the study. The normal control group $(n=8)$ received 
vitamin E-free corn oil (the vehicle of tocotrienol) orally daily and normal saline (the vehicle of buserelin) subcutaneously daily. The buserelin control $(\mathrm{BuC})(\mathrm{n}=8)$ received vitamin E-free corn oil orally daily and subcutaneous buserelin injection $(75 \mu \mathrm{g} / \mathrm{kg} /$ day $)$. The calcium control $(\mathrm{n}=8)$ received $1 \%$ calcium in drinking water and subcutaneous buserelin injection $(75 \mu \mathrm{g} / \mathrm{kg} /$ day $)$ daily. The remaining rats were treated daily with annatto tocotrienol orally at either $60 \mathrm{mg} / \mathrm{kg} /$ day $(\mathrm{n}=8)$ or $100 \mathrm{mg} / \mathrm{kg} /$ day $(\mathrm{n}=8)$ plus daily subcutaneous buserelin injection $(75 \mu \mathrm{g} / \mathrm{kg})(\mathrm{n}=8)$. The experimental protocol was reviewed and approved by Universiti Kebangsaan Malaysia Animal Ethics Committee (Approval Code: FP/FAR/2015/CHIN/29-JULY/698JULY-2015-MAY-2017). The guidelines of animal handling were based on the Principles and Guide to Ethical Use of Laboratory Animals set by the Laboratory Animal Research Unit, Faculty of Medicine, Universiti Kebangsaan Malaysia.

\section{X-ray microcomputed tomography $(\mu \mathrm{CT})$}

$\mathrm{X}$-ray $\mu \mathrm{CT}$ scanning of the harvested tibia was performed using the Skyscan 1076 Scanner (Skyscan, Kartuizersweg Kontich, Belgium). The energy selected for this study was set at $70 \mathrm{kVp}$ and $100 \mu \mathrm{A}$ with high image resolution to obtain the best contrast between bone and soft tissues. The volume of interest (200 slices) selected for trabecular bone parameter was at the proximal metaphysis of the left tibia located $1.5 \mathrm{~mm}$ below the lowest point of the epiphyseal growth plate extending distally. For the cortical bone parameters, 100 slices were analyzed at the diaphysis region located $2.5 \mathrm{~mm}$ distal to the proximal metaphysis of the same tibia (Figure 1).

\section{Bone calcium content}

The left femur cleaned of soft tissues was dried in an oven at $100^{\circ} \mathrm{C}$ for 24 hours. Next, it was ashed at $800^{\circ} \mathrm{C}$ for 12 hours. The end product was weighed and dissolved in $3 \mathrm{~mL}$ of nitric acid (Fisher Scientific, Shah Alam Selangor, Malaysia). Then, it was diluted in lanthanum chloride (Sigma-Aldrich Co., St Louis, MO, USA). The calcium content of the solution was determined by an atomic absorption spectrophotometer (AA-689; Shimadzu, Kyoto, Japan) at the wavelength of $422.7 \mathrm{~nm}$.

\section{Biomechanical strength}

A precision universal tester (Autograph AG-10kNG; Shimadzu) with Trapezium X materials testing operation software was used to evaluate the biochemical strength of

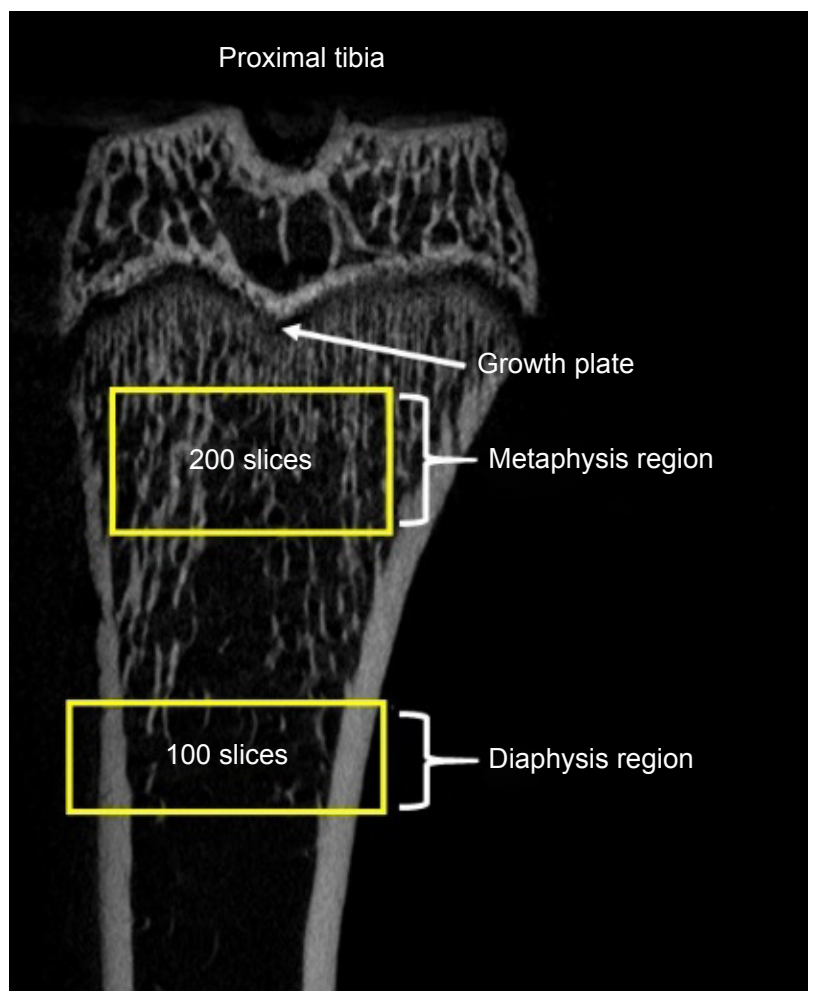

Figure I $\mu \mathrm{CT}$ analysis on proximal tibia.

Notes: The volume of interest scanned using $\mu \mathrm{CT}$ is depicted in the figure. The trabecular parameters are derived from the region (200 slices) located $1.5 \mathrm{~mm}$ below the growth plate of the tibia. The cortical parameters are derived from the region (100 slices) located $2.5 \mathrm{~mm}$ distal to the proximal metaphysis.

Abbreviation: $\mu \mathrm{CT}$, microcomputed tomography.

left femur. A three-point bending test was conducted on the femur cleaned of soft tissues. It was placed on an aluminum base, with the dorsal proximal femur placed on the onerounded edge-free notch while the distal diaphysis at the synostosis on the other side. The femur was moistened with PBS throughout the test. The roller stamp with the tip consisting of axle-led aluminum was driven down at the central femoral diaphysis (speed $5 \mathrm{~mm} / \mathrm{min}$; span length $10 \mathrm{~mm}$ ) until the primary strength of $1 \mathrm{~N}$ was achieved (Figure 2). The study ended automatically once a loss of force $>20 \mathrm{~N}$ or a linear change of $2 \mathrm{~mm}$ was detected upon fracturing of the femur midshaft to avoid bursting of the specimens. The Trapezium X software was then used to analyze load $(\mathrm{N})$, displacement $(\mathrm{mm})$, stress $\left(\mathrm{N} / \mathrm{mm}^{2}\right)$, strain $(\%)$, and elasticity $\left(\mathrm{N} / \mathrm{mm}^{2}\right)$.

\section{Statistical analysis}

Shapiro-Wilk test was used to assess the normality of the data. The change in $\mu \mathrm{CT}$ parameters, calcium content, and bone biomechanical strength parameters was compared using one-way analysis of variance with post 


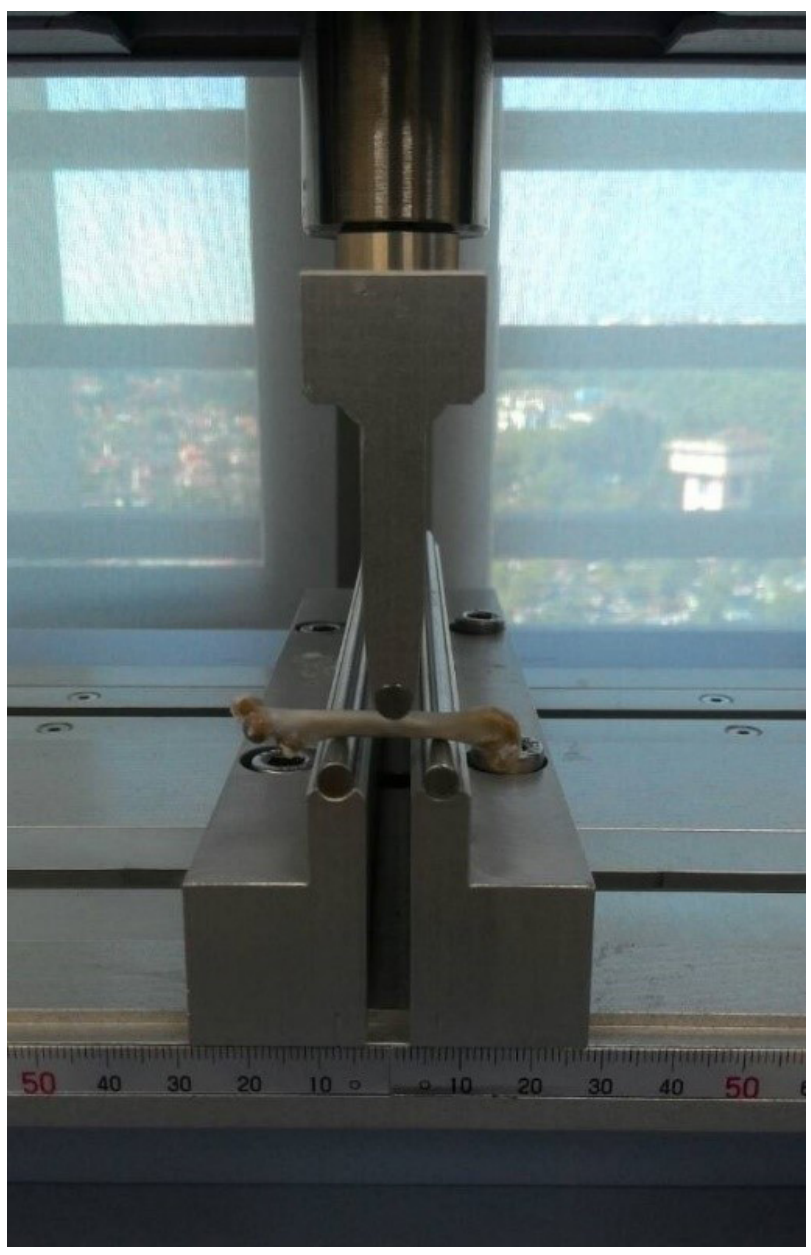

Figure 2 Biomechanical strength test on femur.

Notes: The biomechanical strength of the femur is tested using a three-point bending test. A load is applied on the midshaft of the femur until it fractures.

hoc pairwise comparison. All data were reported using mean \pm standard error of the mean. Data analysis was performed using SPSS, version 20.0 (IBM Corporation, Armonk, NY, USA). A two-tailed $P$-value of $<0.05(P<0.05)$ was considered statistically significant.

\section{Results}

Buserelin caused a significant reduction in bone volume, connective density as well as a significant increase in trabecular separation at the proximal tibia compared with the normal control $(P<0.05)$. Annatto tocotrienol at both doses and calcium supplementation prevented these degenerative changes in the rats treated with buserelin $(P<0.05)$. Trabecular thickness and structural model index were similar across all the study groups $(P>0.05)$ (Figure 3$)$.

The cortical structural parameters including total area, cortical area, and percentage of cortical over total area were not significantly different among all the study groups
$(P>0.05)$. However, cortical thickness was significantly increased in the rats treated with annatto tocotrienol at 60 and $100 \mathrm{mg} / \mathrm{kg}$ compared with the buserelin group $(P<0.05)$ (Figure 4).

Figure 5 shows the three-dimensional reconstruction of trabecular and cortical bones at the tibia of male rats after 3 months of treatment. Deterioration of trabecular bone was apparent for the BuC group. Trabecular bone was denser in the annatto tocotrienol-treated group (60 and $100 \mathrm{mg} / \mathrm{kg}$ ) compared with the buserelin-treated groups. Cortical bone appeared to be thicker in the annatto tocotrienol-treated group compared with the BuC group.

Bone calcium level was significantly lower in the $\mathrm{BuC}$ compared with the normal control group $(P>0.05)$. Both calcium and annatto tocotrienol (60 and $100 \mathrm{mg} / \mathrm{kg}$ ) prevented the decrease in bone calcium level in the buserelin-treated rats $(P<0.05)$ (Figure 6).

Buserelin decreased biomechanical strength of the bone, indicated by a significant reduction in maximum load, strain, and elasticity of the buserelin-treated group compared with the normal control $(P<0.05)$. Treatment with calcium and buserelin (60 and $100 \mathrm{mg} / \mathrm{kg}$ ) prevented the decrease in load and elasticity $(P<0.05)$. Furthermore, annatto tocotrienol at 60 and $100 \mathrm{mg} / \mathrm{kg}$ also increased the femoral stress value. Only annatto tocotrienol at $60 \mathrm{mg} / \mathrm{kg}$ prevented the reduction in strain parameter $(P<0.05)$. There were no significant changes in displacement and stiffness among all the study groups $(P>0.05)$ (Figure 7$)$.

\section{Discussion}

The use of GnRH agonists, such as buserelin, is associated with a higher degree of bone loss in men. ${ }^{29,30}$ Our study showed that annatto tocotrienol can prevent the degenerative changes of the bone in rats receiving buserelin. Three closely associated aspects of bone health, ie, bone microstructure, calcium content, and biomechanical strength, were showcased in this study. As biomechanical strength is determined by both geometry and material properties of the bone, any changes in microstructure and calcium content would be reflected by the bone strength. ${ }^{31}$ Annatto tocotrienol improved all three aspects of bone health, and its effects were comparable with calcium supplementation in this study.

The normal control group did not show any significant changes in all bone parameters compared with the baseline group. This is in agreement with previous studies showing that the bone did not experience significant modeling or deterioration within this life stage of male rats. ${ }^{32}$ The lack of changes between baseline and control also showed that 


\section{A}
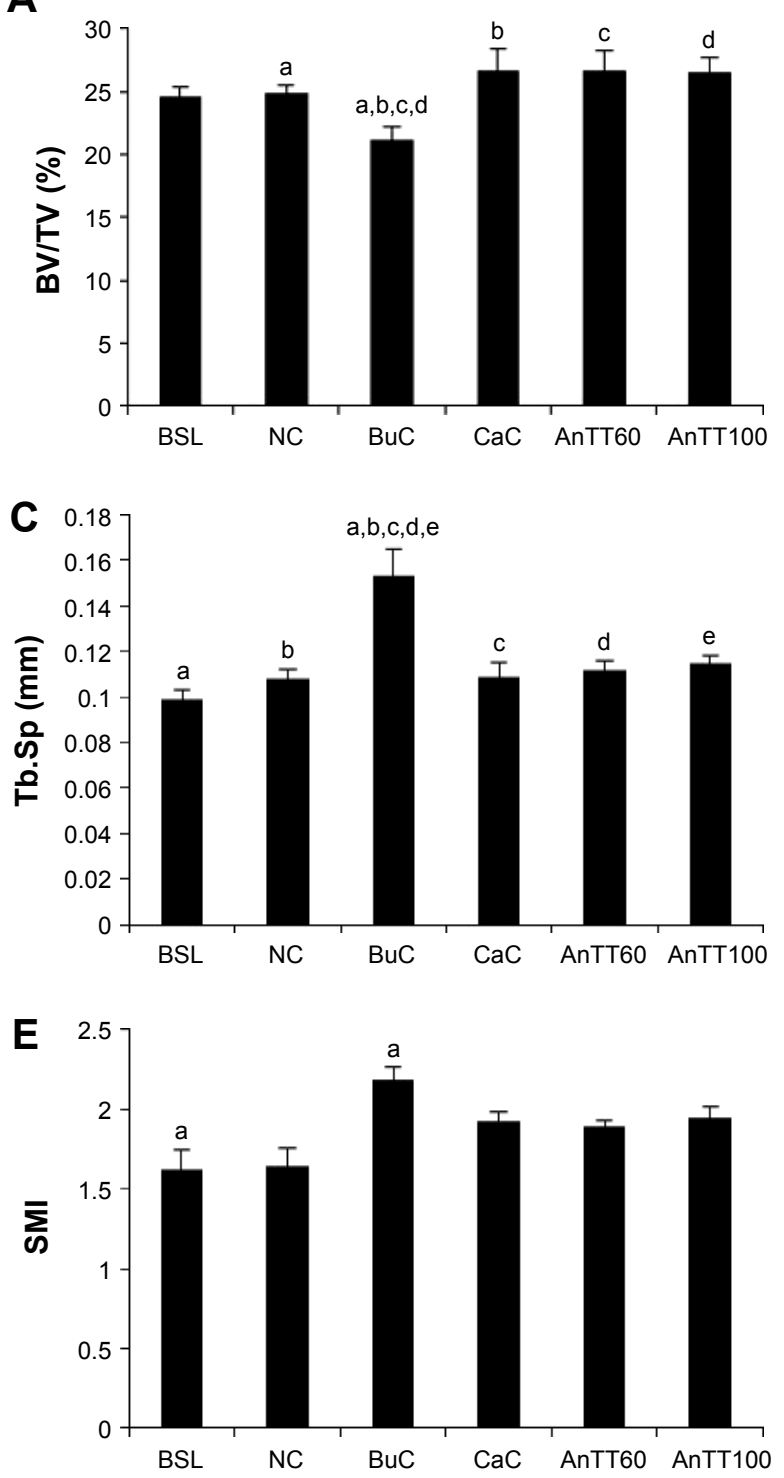

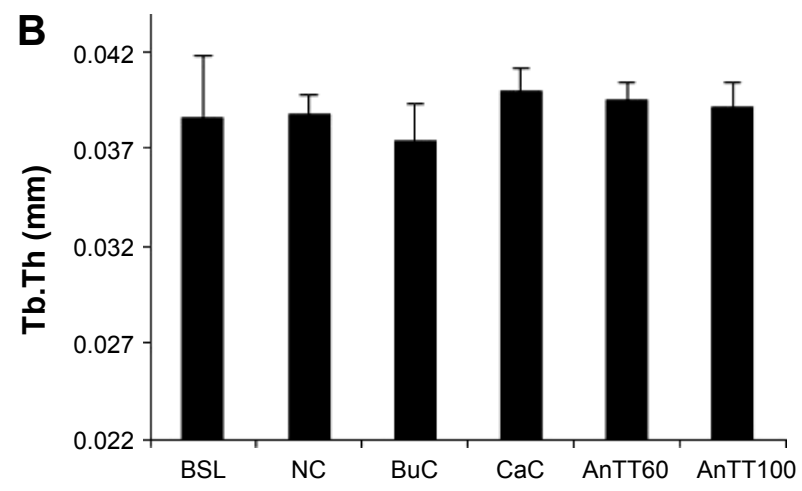

D

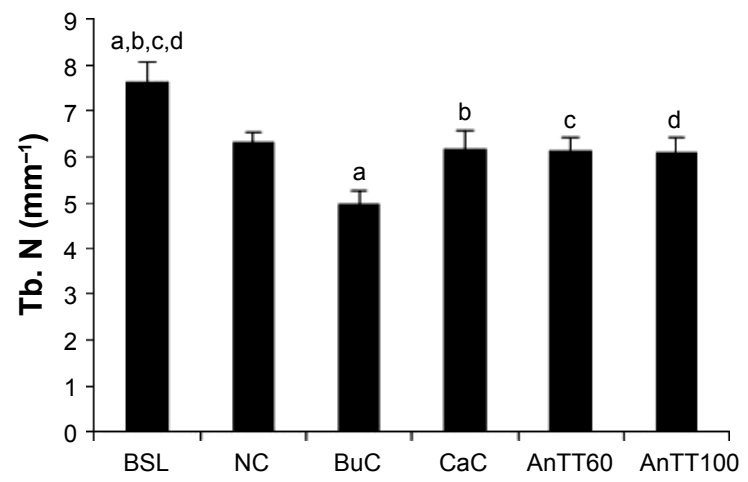

F

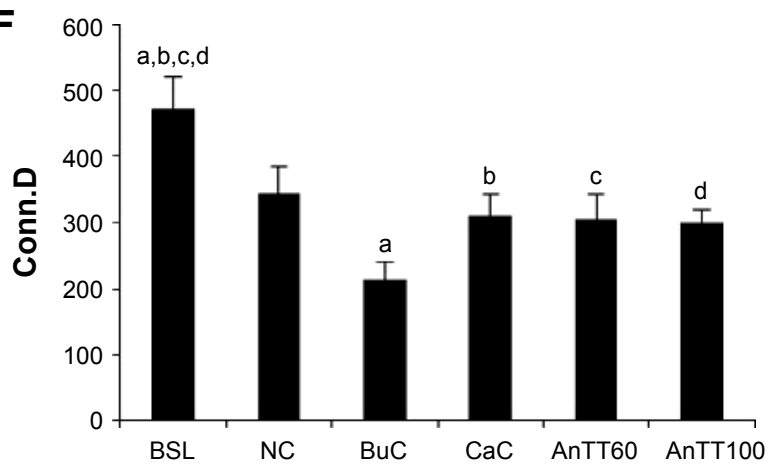

Figure 3 Trabecular bone indices in the proximal tibia of the rats evaluated using $\mu \mathrm{CT}$.

Notes: The bar charts show the trabecular bone indices in the proximal tibia of the rats evaluated using $\mu \mathrm{CT}$, ie, bone volume/total volume (A), trabecular number (B), trabecular thickness (C), trabecular separation (D), structural model index (E), and connectivity density (F). The data are shown as mean \pm standard error of the mean. Same letters $(\mathrm{a}-\mathrm{e})$ indicate a significant difference between groups in each parameter. The statistical significant value set as $P<0.05$. BuC, buserelin control group; $\mathrm{CaC}$, calcium control group; AnTT60, annatto-tocotrienol $60 \mathrm{mg} / \mathrm{kg}$ group; AnTTI00, annatto-tocotrienol $100 \mathrm{mg} / \mathrm{kg}$ group.

Abbreviations: BSL, baseline; NC, normal control; $\mu \mathrm{CT}$, microcomputed tomography; SMI, structural model index; BV/TV, bone volume; Tb.Th, trabecular thickness; Tb.Sp, trabecular separation; Tb.N, trabecular number; Conn.D, connectivity density.

any bone alternations observed during the experiment were caused by the treatment rather than the age of the rats. Buserelin induced significant deterioration of trabecular bone structure and bone calcium content after 3 months in this study. Tobias et $\mathrm{l}^{33}$ reported that buserelin treatment for 90 days induced a significant decrease in bone volume, trabecular number, and thickness in female rats for 90 days. This occurred due to high bone turnover and calcium mobilization in rats receiving buserelin, evidenced by elevated urinary calcium and hydroxyproline. This ultimately resulted in a lower femur and total body calcium in female rats after 2 weeks of buserelin treatment. ${ }^{34}$ We speculate that similar high bone turnover happened in the male rats receiving buserelin in this study, but markers of bone remodeling and calcium homeostasis were not tested. Hence, the exact mechanism of calcium loss from the femoral bone could not be confirmed. However, it is evident that the loss of microarchitecture (geometry properties) and calcium content (material properties) of the bone resulted in the decline of bone biomechanical strength in the buserelin-treated group.

The negative effects of buserelin on trabecular bone structure, bone calcium content, and femoral biomechanical 
A
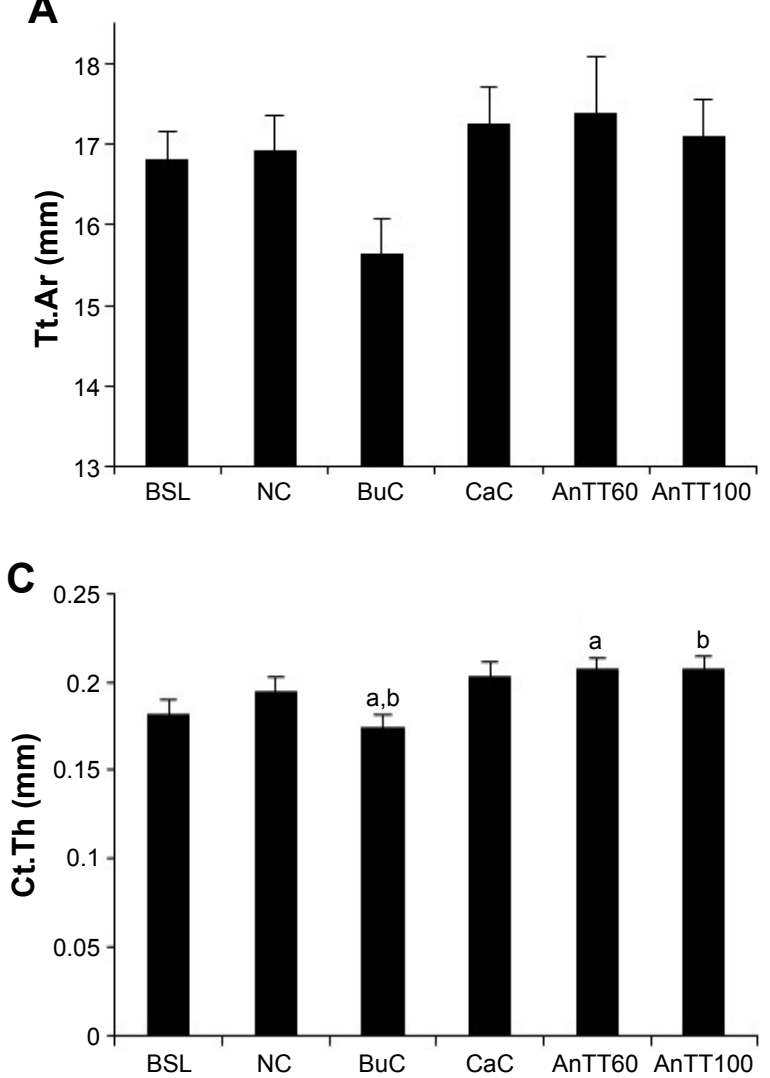

B

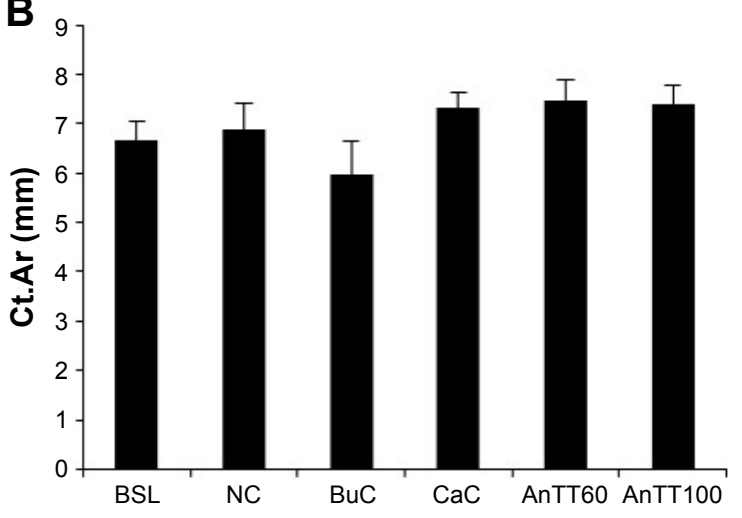

D 50

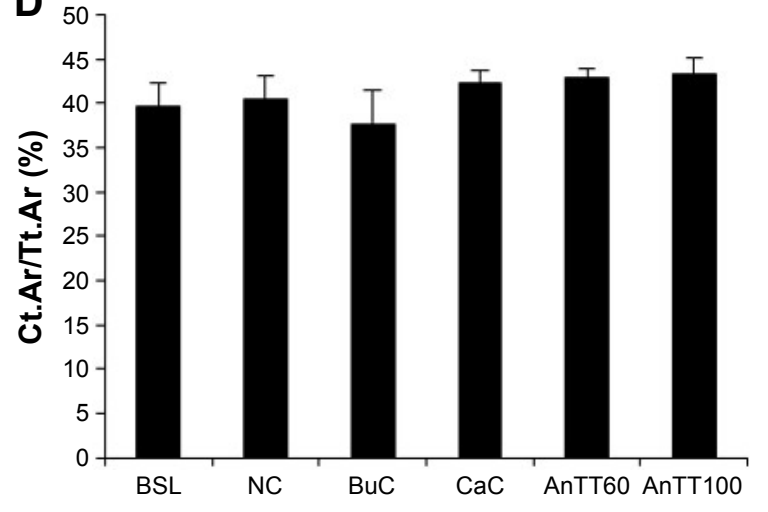

Figure 4 Cortical bone indices in the proximal tibia of the rats evaluated using $\mu \mathrm{CT}$.

Notes: The bar charts show the cortical bone indices in the proximal tibia of the rats evaluated using $\mu$ CT, ie, total area (A), cortical area (B), cortical thickness (C), and cortical area/total area (D). The data are shown as mean \pm standard error of the mean. Same letters (a and b) indicate a significant difference between groups in each parameter. The statistical significant value set as $P<0.05$. BuC, buserelin control group; CaC, calcium control group; AnTT60, annatto-tocotrienol $60 \mathrm{mg} / \mathrm{kg}$ group; AnTTI00, annatto-tocotrienol $100 \mathrm{mg} / \mathrm{kg}$ group.

Abbreviations: BSL, baseline; NC, normal control; $\mu \mathrm{CT}$, microcomputed tomography; Tt.Ar, total area; Ct.Ar, cortical area; Ct.Th, cortical thickness; Ct.Ar/Tt.Ar, cortical area over total area.

strength were reversed by annatto tocotrienol treatment. The skeletal protective effects of annatto tocotrienol were comparable to calcium supplementation. Chin et a ${ }^{17}$ demonstrated that annatto tocotrienol at $60 \mathrm{mg} / \mathrm{kg}$ prevented bone loss in orchidectomized rats by increasing the expression of bone formation genes, such as collagen type I alpha 1, alkaline phosphatase, and beta-catenin, as well as decreasing the expression of receptor activator of nuclear factor

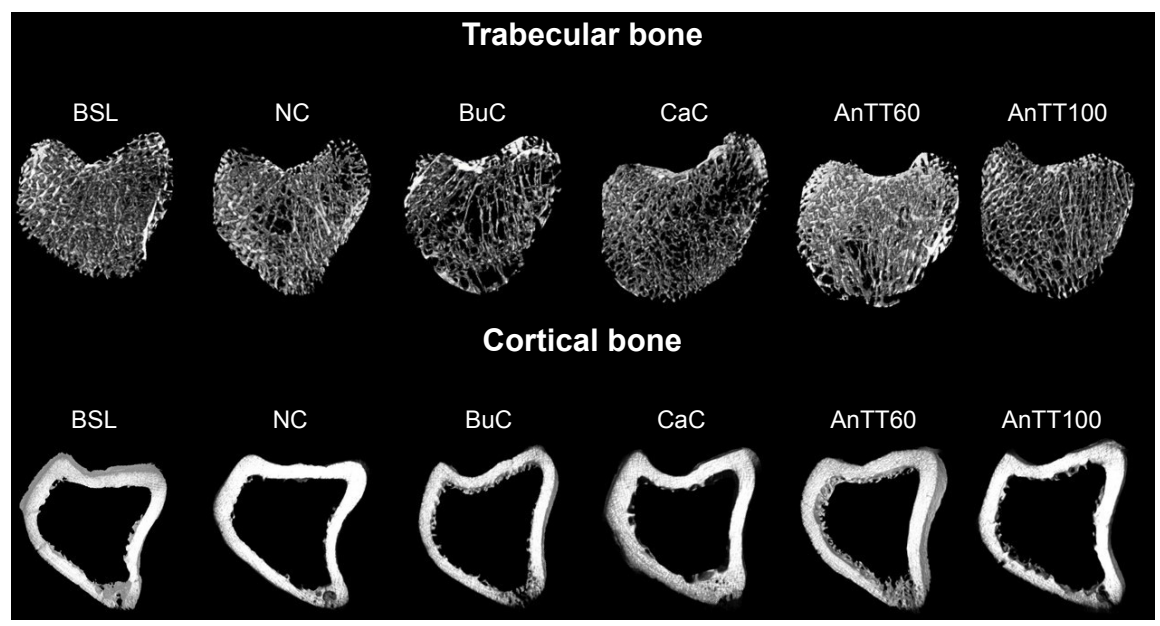

Figure 5 Three-dimensional $\mu \mathrm{CT}$ images of the trabecular and cortical microstructure of distal tibia metaphysis.

Notes: BuC, buserelin control group; $\mathrm{CaC}$, calcium control group; AnTT60, annatto-tocotrienol $60 \mathrm{mg} / \mathrm{kg}$ group; AnTTI00, annatto-tocotrienol I00 mg/kg group. Abbreviations: BSL, baseline; NC, normal control; $\mu \mathrm{CT}$, microcomputed tomography. 


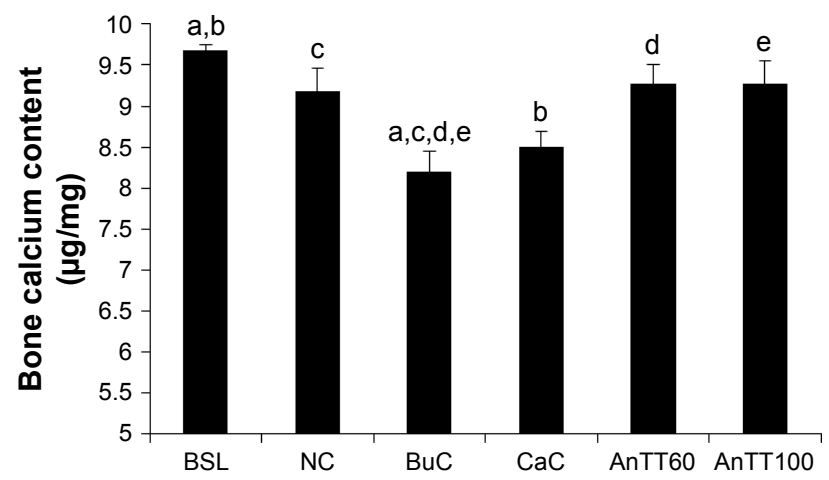

Figure 6 Posttreatment bone calcium level in rats.

Notes: The bar charts show the posttreatment bone calcium level in rats. The data are shown as mean \pm standard error of the mean. Same letters $(a-e)$ indicate a significant difference between groups in each parameter. The statistical significant value set as $P<0.05$. BuC, buserelin control group; $\mathrm{CaC}$, calcium control group; AnTT60, annatto-tocotrienol $60 \mathrm{mg} / \mathrm{kg}$ group; AnTTI00, annatto-tocotrienol $100 \mathrm{mg} / \mathrm{kg}$ group. Abbreviations: BSL, baseline; NC, normal control.

kappa-B ligand, a stimulator of osteoclast formation. AbdulMajeed et $\mathrm{al}^{35}$ also showed that concurrent administration of delta-tocotrienol $(60 \mathrm{mg} / \mathrm{kg})$ and lovastatin $(11 \mathrm{mg} / \mathrm{kg})$ significantly increased bone formation and reduced bone resorption in ovariectomized rats after 8 weeks. This was achieved by upregulating the gene expression of bone morphogenetic protein-2. The previous studies did not examine the effects of tocotrienol on cortical bone. Our study showed that although cortical bone did not decline significantly in rats, annatto tocotrienol at both doses increased cortical
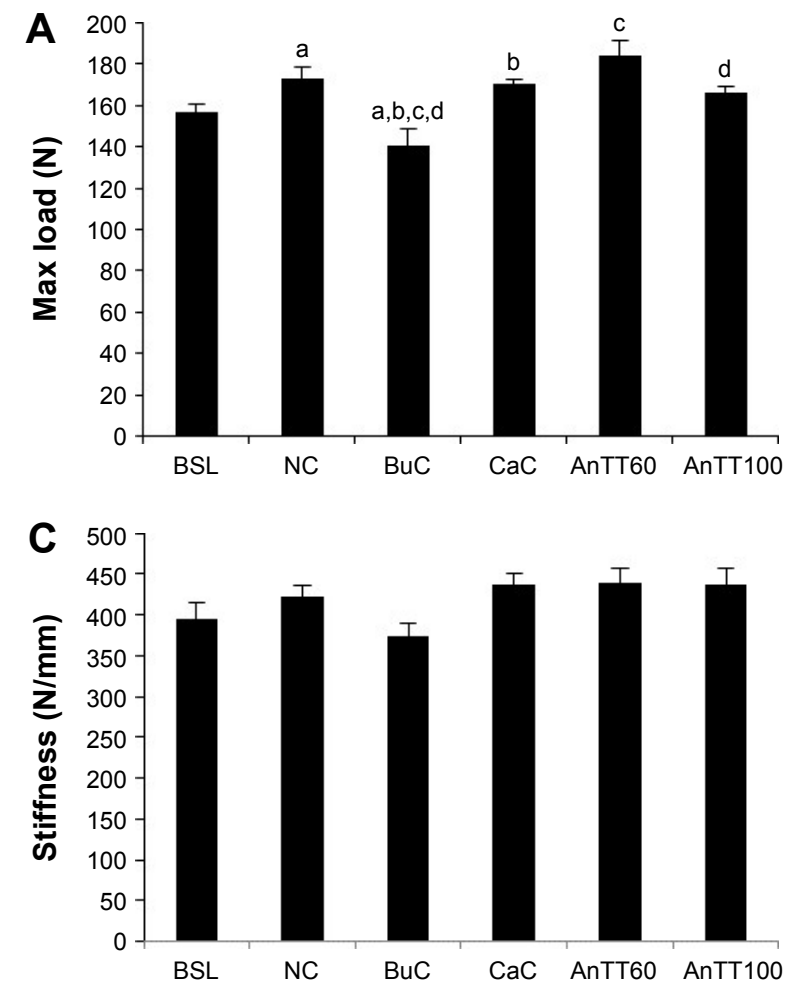

Figure 7 (Continued) thickness. This reflected a strong skeletal anabolic effect of annatto tocotrienol.

Calcium in the form of hydroxyapatite is the principal inorganic component of bone. ${ }^{36} \mathrm{~A}$ balance calcium homeostasis is important to ensure the integrity of the skeleton. ${ }^{37}$ Excess mobilization of calcium from the bone reserve to the circulation will cause osteoporosis. The calcium conserving effects of tocotrienol have been demonstrated by previous studies. Norazlina et $\mathrm{a}^{38}$ indicated that alpha-tocopherol was essential for normal calcium metabolism. An alpha-tocopheroldeficient diet could induce bone loss in animals. ${ }^{38}$ Despite not being an essential nutrient in the body, supplementation of tocotrienol could protect skeletal calcium loss in various models of osteoporosis. Chin et $\mathrm{al}^{21}$ showed that treatment of annatto tocotrienol $(60 \mathrm{mg} / \mathrm{kg})$ preserved the calcium level in orchidectomized rats after 2 months of treatment. Gammatocotrienol $(60 \mathrm{mg} / \mathrm{kg}$ ) for 8 weeks prevented calcium loss at the fourth lumbar vertebra of the rats treated by dexamethasone. ${ }^{20}$ Our studies reaffirmed the previous findings and further showed that the effect of annatto tocotrienol on bone calcium content was comparable to calcium supplementation. However, we did not conduct calcium isotopic test to determine the increase in bone calcium content, which could be due to increased absorption, decreased excretion, or both.

Biomechanical test is the gold standard used for the assessment of bone strength. ${ }^{39}$ Few studies have examined
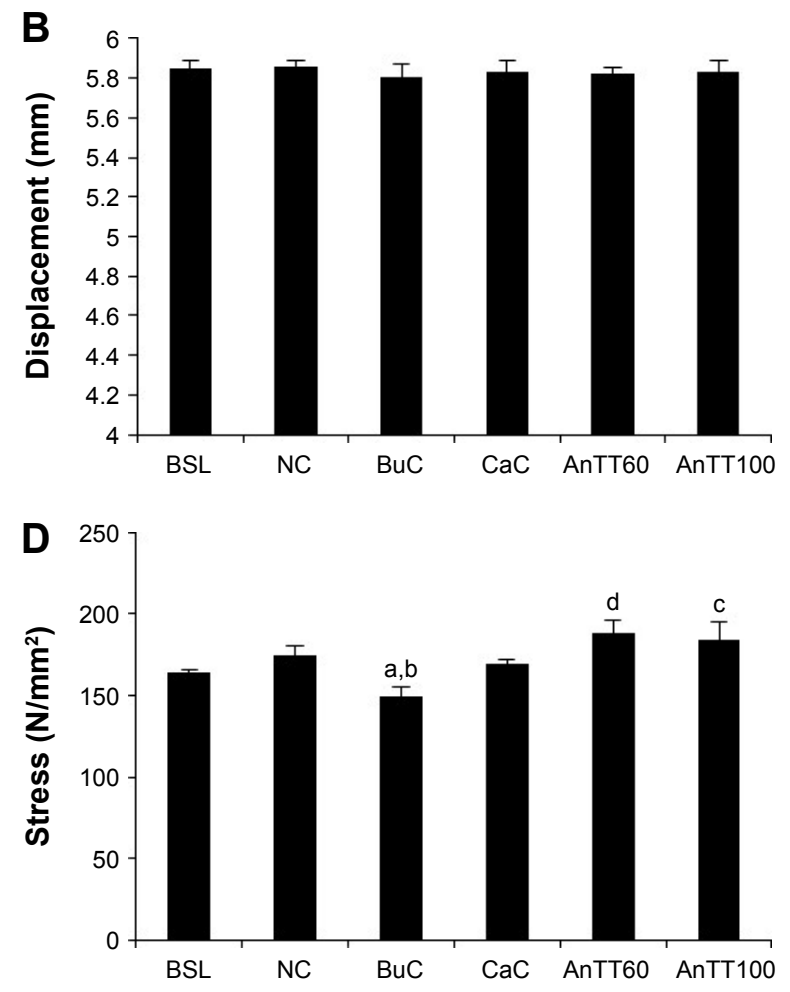

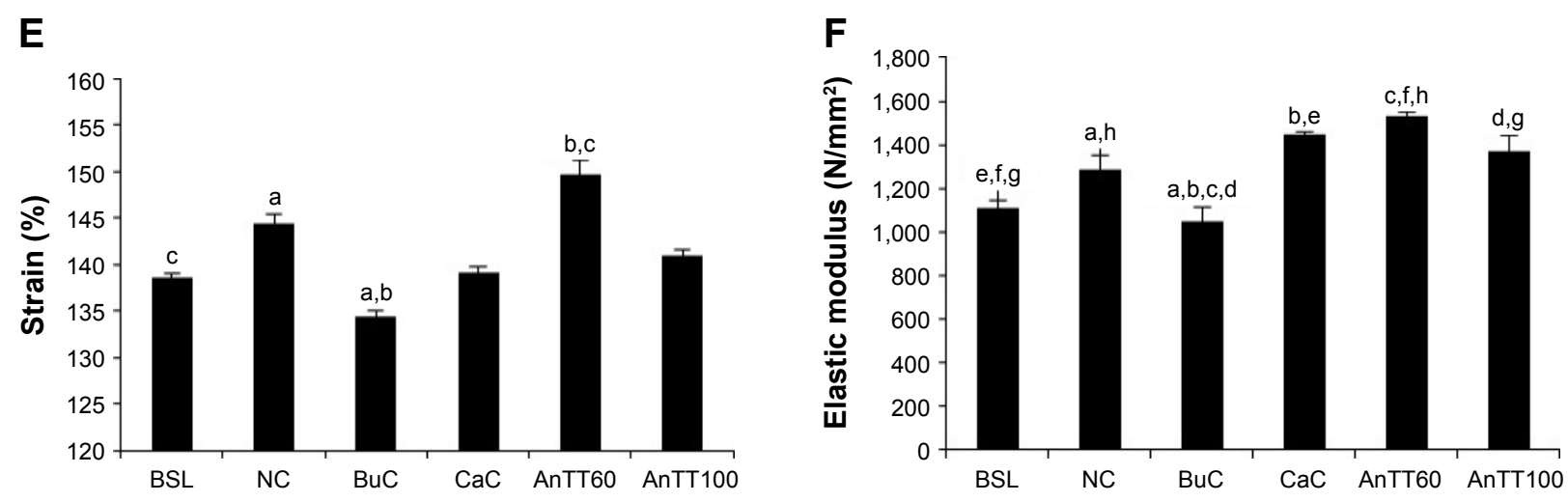

Figure 7 Posttreatment biomechanical strength parameters of the left femur.

Notes: The bar charts show the posttreatment biomechanical strength parameters of the left femur, ie, maximum load (A), displacement (B), stiffness (C), stress (D), strain $(\mathbf{E})$, and elastic modulus $(\mathbf{F})$. The data are shown as mean \pm standard error of the mean. Same letters (a-h) indicate a significant difference between groups in each parameter. The statistical significant value set as $P<0.05$. BuC, buserelin control group; CaC, calcium control group; AnTT60, annatto-tocotrienol 60 mg/kg group; AnTTI00, annatto-tocotrienol $100 \mathrm{mg} / \mathrm{kg}$ group.

Abbreviations: BSL, baseline; NC, normal control.

effects of tocotrienol on bone strength. In this study, the bone of the rats treated with annatto tocotrienol 60 and $100 \mathrm{mg} / \mathrm{kg}$ showed significant improvement in both extrinsic (load) and intrinsic biomechanical parameters (stress, strain, and elasticity). Load, reflected by the maximum amount of force needed to break the bone, represents the whole bone strength. ${ }^{40}$ Femoral bones of the rats receiving annatto tocotrienol at both doses and calcium supplementation had greater strength because they withstood greater load than the untreated group. Stress is the strength of the bone tissue under a given loading condition. ${ }^{41}$ Femoral bones of the annatto tocotrienol at both doses and calcium groups had a higher stress value compared with the untreated group. This indicated that the femurs of the treated groups absorbed a higher load before fracturing. Only annatto tocotrienol at dose $60 \mathrm{mg} / \mathrm{kg}$ significantly enhanced the strain of the femoral bone, indicating a better ability of the bone to withstand deformation. Elasticity is the ability of the bone to return its shape after removing the load. ${ }^{42}$ Similar to previous indices, rats treated with annatto tocotrienol at both doses and calcium supplementation had a higher elasticity compared with the untreated group. Hence, the overall bone strength in the rats receiving annatto tocotrienol was greater than the untreated group and comparable to the calcium control. Shuid et $\mathrm{al}^{43}$ showed that treatment of gamma-tocotrienol at $60 \mathrm{mg} / \mathrm{kg}$ significantly improved biomechanical strength of the femur in normal rats. The enhanced bone calcium content and bone microstructure caused by annatto tocotrienol had translated to a better bone biomechanical strength in the rats treated with annatto tocotrienol in this study.

Several limitations should be considered when interpreting the results of the present study. Only oral administration of annatto tocotrienol was tested in this study. A previous study established that the bioavailability of tocotrienol varied significantly according to the routes of administration, whereby the oral route was shown to have higher bioavailability compared to intramuscular and intraperitoneal injections. ${ }^{44}$ Subcutaneous injection was shown to deposit reasonable amount of tocotrienol in the bone, ${ }^{45}$ but it does not resemble the method of intake in humans. Biomechanical strength and bone calcium content were tested at the femur, but microstructural indices were obtained from the tibia. Due to the variation of trabecular and cortical bone at different sites, they might not correlate well with each other. Tibia, which is richer in trabecular bone, was expected to show a more rapid response to androgen deprivation and treatments than the femur. Annatto tocotrienol did not show dose-dependent effects on the bone in this study, whereby the skeletal improvement of the rats receiving $60 \mathrm{mg} / \mathrm{kg}$ annatto tocotrienol was similar to those receiving $100 \mathrm{mg} / \mathrm{kg}$. We postulated that the maximal therapeutic potential of annatto tocotrienol on bone has been reached at $60 \mathrm{mg} / \mathrm{kg}$. However, this speculation awaits evidence from extensive pharmacokinetic-pharmacodynamic studies.

This is the first study to demonstrate the effects of annatto tocotrienol in a male osteoporotic model induced by buserelin. The skeletal effects of tocotrienol were comparable to calcium, indicating that it might provide a potential alternative for the prevention of osteoporosis. Since the rats were not deficient in dietary calcium at the first place, annatto tocotrienol might work for osteoporotic men with adequate calcium intake. The effects of tocotrienol in combination with calcium supplement in calcium deficiency model would be explored in further studies. 


\section{Conclusion}

Annatto tocotrienol at $60 \mathrm{mg} / \mathrm{kg}$ can prevent deterioration of trabecular bone induced with buserelin by preserving the microstructural integrity, calcium content, and biomechanical strength of the bone. Further increasing the dose of annatto tocotrienol does not provide added skeletal improvement. Tocotrienol may be useful to prevent bone loss in male patients using GnRH agonists.

\section{Acknowledgments}

We thank Universiti Kebangsaan Malaysia for funding the researchers via GUP-2017-060 and FF-2016-430 grants. We express our gratitude to American River Nutrition for providing the annatto tocotrienol. We also thank Mr Azlan Mohd Arlamsyah, Mr Fadhlullah Zuhair Japar Sidik, Mr Muhamad Arizi Aziz, and Mr Mohd Mustazil Mohd Noor from the Department of Pharmacology for their technical assistance.

\section{Author contributions}

All authors made substantial contributions to conception and design, acquisition of data, or analysis and interpretation of data; took part in drafting the article or revising it critically for important intellectual content; gave final approval of the version to be published; and agree to be accountable for all aspects of the work.

\section{Disclosure}

The authors report no conflicts of interest in this work.

\section{References}

1. Johnell O, Kanis J. Epidemiology of osteoporotic fractures. Osteoporos Int. 2005;16(2):S3-S7.

2. Klibanski A, Adams-Campbell L, Bassford T, et al. Osteoporosis prevention, diagnosis, and therapy. J Am Med Assoc. 2001;285(6):785-795.

3. Panday K, Gona A, Humphrey MB. Medication-induced osteoporosis: screening and treatment strategies. Ther Adv Musculoskelet Dis. 2014; 6(5): $185-202$

4. Smith MR, McGovern FJ, Zietman AL, et al. Pamidronate to prevent bone loss during androgen-deprivation therapy for prostate cancer. $N E n g l$ J Med. 2001;345(13):948-955.

5. Ahmadi H, Daneshmand S. Androgen deprivation therapy for prostate cancer: long-term safety and patient outcomes. Patient Relat Outcome Meas. 2014;5:63-70.

6. Loblaw DA, Mendelson DS, Talcott JA, et al. American Society of Clinical Oncology recommendations for the initial hormonal management of androgen-sensitive metastatic, recurrent, or progressive prostate cancer. J Clin Oncol. 2004;22(14):2927-2941.

7. Smith MR, Boyce SP, Moyneur E, Duh MS, Raut MK, Brandman J. Risk of clinical fractures after gonadotropin-releasing hormone agonist therapy for prostate cancer. $J$ Urol. 2006;175(1):136-139.

8. Lin X, Xiong D, Peng Y-Q, et al. Epidemiology and management of osteoporosis in the People's Republic of China: current perspectives. Clin Interv Aging. 2015;10:1017.
9. Teng GG, Curtis JR, Saag KG. Mortality and osteoporotic fractures: is the link causal, and is it modifiable? Clin Exp Rheumatol. 2008; 26(5 Suppl 51):S125-S137.

10. Budhia S, Mikyas Y, Tang M, Badamgarav E. Osteoporotic fractures. Pharmacoeconomics. 2012;30(2):147-170.

11. Banu J. Causes, consequences, and treatment of osteoporosis in men. Drug Des Devel Ther. 2013;7:849.

12. Kaufman J-M, Reginster J-Y, Boonen S, et al. Treatment of osteoporosis in men. Bone. 2013;53(1):134-144.

13. Colombo ML. An update on vitamin E, tocopherol and tocotrienol perspectives. Molecules. 2010;15(4):2103-2113.

14. Aggarwal BB, Sundaram C, Prasad S, Kannappan R. Tocotrienols, the vitamin $\mathrm{E}$ of the 21st century: its potential against cancer and other chronic diseases. Biochem Pharmacol. 2010;80(11):1613-1631.

15. Muhammad N, Luke DA, Shuid AN, Mohamed N, Soelaiman I-N. Two different isomers of vitamin e prevent bone loss in postmenopausal osteoporosis rat model. Evid Based Complement Alternat Med. 2012; 2012:161527.

16. Soelaiman IN, Ming W, Abu Bakar R, et al. Palm tocotrienol supplementation enhanced bone formation in oestrogen-deficient rats. Int $J$ Endocrinol. 2012;2012:532862.

17. Chin K-Y, Ima-Nirwana S. Effects of annatto-derived tocotrienol supplementation on osteoporosis induced by testosterone deficiency in rats. Clin Interv Aging. 2014;9:1247.

18. Ahmad N, Khalid B, Luke D, Ima Nirwana S. Tocotrienol offers better protection than tocopherol from free radical-induced damage of rat bone. Clin Exp Pharmacol Physiol. 2005;32(9):761-770.

19. Hermizi H, Faizah O, Ima-Nirwana S, Nazrun SA, Norazlina M. Beneficial effects of tocotrienol and tocopherol on bone histomorphometric parameters in Sprague-Dawley male rats after nicotine cessation. Calcif Tissue Int. 2009;84(1):65-74.

20. Ima-Nirwana S, Suhaniza S. Effects of tocopherols and tocotrienols on body composition and bone calcium content in adrenalectomized rats replaced with dexamethasone. J Med Food. 2004;7(1):45-51.

21. Chin K-Y, Gengatharan D, Mohd Nasru FS, et al. The effects of annatto tocotrienol on bone biomechanical strength and bone calcium content in an animal model of osteoporosis due to testosterone deficiency. Nutrients. 2016;8(12):808

22. Frega N, Mozzon M, Bocci F. Identification and estimation of tocotrienols in the annatto lipid fraction by gas chromatography-mass spectrometry. J Am Oil Chem Soc. 1998;75(12):1723-1727.

23. Ng MH, Choo YM, Ma AN, Chuah CH, Hashim MA. Separation of vitamin $\mathrm{E}$ (tocopherol, tocotrienol, and tocomonoenol) in palm oil. Lipids. 2004;39(10):1031-1035.

24. Stöggl W, Huck C, Wongyai S, Scherz H, Bonn G. Simultaneous determination of carotenoids, tocopherols, and $\gamma$-oryzanol in crude rice bran oil by liquid chromatography coupled to diode array and mass spectrometric detection employing silica C30 stationary phases. J Sep Sci. 2005;28(14):1712-1718.

25. Khor HT, Ng TT. Effects of administration of alpha-tocopherol and tocotrienols on serum lipids and liver HMG CoA reductase activity. Int J Food Sci Nutr. 2000;51(Suppl):S3-S11.

26. Qureshi AA, Pearce BC, Nor RM, Gapor A, Peterson DM, Elson CE. Dietary alpha-tocopherol attenuates the impact of gamma-tocotrienol on hepatic 3-hydroxy-3-methylglutaryl coenzyme A reductase activity in chickens. J Nutr. 1996;126(2):389-394.

27. Hosomi A, Arita M, Sato Y, et al. Affinity for alpha-tocopherol transfer protein as a determinant of the biological activities of vitamin $E$ analogs. FEBS Lett. 1997;409(1):105-108.

28. Fujita K, Iwasaki M, Ochi H, et al. Vitamin E decreases bone mass by stimulating osteoclast fusion. Nat Med. 2012;18(4):589-594.

29. Maillefert J, Sibilia J, Michel F, Saussine C, Javier R, Tavernier C. Bone mineral density in men treated with synthetic gonadotropin-releasing hormone agonists for prostatic carcinoma. J Urol. 1999;161(4):1219-1222.

30. Stoch SA, Parker RA, Chen L, et al. Bone loss in men with prostate cancer treated with gonadotropin-releasing hormone agonists 1. J Clin Endocrinol Metab. 2001;86(6):2787-2791. 
31. Chavassieux P, Seeman E, Delmas P. Insights into material and structural basis of bone fragility from diseases associated with fractures: how determinants of the biomechanical properties of bone are compromised by disease. Endocr Rev. 2006;28(2):151-164.

32. Wronski T, Dann L, Scott K, Cintron M. Long-term effects of ovariectomy and aging on the rat skeleton. Calcif Tissue Int. 1989;45(6): $360-366$.

33. Tobias J, Chambers T, Gallagher A. Effect of administration and subsequent cessation of buserelin on cancellous bone of female rats. J Bone Miner Res. 1994;9(12):1919-1925.

34. Goulding A, Gold E. Buserelin-mediated osteoporosis: effects of restoring estrogen on bone resorption and whole body calcium content in the rat. Calcif Tissue Int. 1990;46(1):14-19.

35. Abdul-Majeed S, Mohamed N, Soelaiman I-N. Effects of tocotrienol and lovastatin combination on osteoblast and osteoclast activity in estrogen-deficient osteoporosis. Evid Based Complement Alternat Med. 2012;2012:960742.

36. Legros R, Balmain N, Bonel G. Age-related changes in mineral of rat and bovine cortical bone. Calcif Tissue Int. 1987;41(3):137-144.

37. US Department of Health and Human Services. Bone Health and Osteoporosis: A Report of the Surgeon General. Rockville: US Department of Health and Human Services, Office of the Surgeon General; 2004:87.

38. Norazlina M, Ima-Nirwana S, Gapor M, Khalid B. Palm vitamin E is comparable to $\alpha$-tocopherol in maintaining bone mineral density in ovariectomised female rats. Exp Clin Endocrinol Diabetes. 2000; 108(04):305-310.
39. Voide R, Van Lenthe GH, Schneider P, et al. Functional microimaging: an integrated approach for advanced bone biomechanics and failure analysis. Paper Presented at: Proceedings of SPIE. 2006; San Diego, CA.

40. Ritchie R, Koester K, Ionova S, Yao W, Lane N, Ager J. Measurement of the toughness of bone: a tutorial with special reference to small animal studies. Bone. 2008;43(5):798-812.

41. Bankoff ADP. Biomechanical Characteristics of the Bone. In: Goswami T, editor. Human Musculoskeletal Biomechanics. London: InTech; 2012:61-86.

42. Einhorn TA. Bone strength: the bottom line. Calcif Tissue Int. 1992; 51(5):333-339.

43. Shuid AN, Mehat Z, Mohamed N, Muhammad N, Soelaiman IN. Vitamin E exhibits bone anabolic actions in normal male rats. $J$ Bone Miner Metab. 2010;28(2):149-156.

44. Yap SP, Yuen KH, Lim AB. Influence of route of administration on the absorption and disposition of alpha-, gamma- and delta-tocotrienols in rats. J Pharm Pharmacol. 2003;55(1):53-58.

45. Deng L, Peng Y, Wu Y, et al. Tissue distribution of emulsified gammatocotrienol and its long-term biological effects after subcutaneous administration. Lipids Health Dis. 2014;13:66.
Drug Design, Development and Therapy

\section{Publish your work in this journal}

Drug Design, Development and Therapy is an international, peerreviewed open-access journal that spans the spectrum of drug design and development through to clinical applications. Clinical outcomes, patient safety, and programs for the development and effective, safe, and sustained use of medicines are the features of the journal, which

\section{Dovepress}

has also been accepted for indexing on PubMed Central. The manuscript management system is completely online and includes a very quick and fair peer-review system, which is all easy to use. Visit http://www.dovepress.com/testimonials.php to read real quotes from published authors. 